\title{
ANALISIS FAKTOR-FAKTOR YANG MEMPENGARUHI LOYALITAS PELANGGAN RETAIL PUPUK UREA NONSUBSIDI PT PUPUK ISKANDAR MUDA DI KABUPATEN ACEH UTARA
}

\author{
Oleh \\ Zainal Abidin, Jullimursyida, Ichsan. \\ PROGRAM PASCASARJANA ILMU MANAJEMEN \\ FAKULTAS EKONOMI DAN BISNIS \\ UNIVERSITAS MALIKUSSALEH
}

\begin{abstract}
This study aims to determine the effect of product excellence and brand trust on customer loyalty through customer satisfaction as an intervening variable. This study uses primary data obtained by distributing questionnaires to 144 respondents, who are the retail customers of non-subsidized urea fertilizer of PT Pupuk Iskandar Muda in the North Aceh Regency. The method used to analyze the data is Structural Equation Modeling (SEM). The results find that brand trust significantly influences customer satisfaction and customer loyalty, but product excellence does not significantly influence customer satisfaction and Retail customer loyalty of non-subsidized urea fertilizer of PT Pupuk Iskandar Muda in North Aceh Regency. Furthermore, customer satisfaction mediates the influence of brand trust on retail customer satisfaction of non-subsidized urea fertilizer of PT Pupuk Iskandar Muda in the North Aceh Regency. Based on the results of the study, it is expected that the leaders of PT Pupuk Iskandar Muda to increase customer loyalty, it is necessary to pay attention to the efforts for growing and increasing brand trust in customers by creating positive perceptions of costumers about the benefits that can be given by the products/brands so that they are confident in using non-subsidized urea fertilizer of PT Pupuk Iskandar Muda in North Aceh Regency
\end{abstract}

Keywords: $\quad$ product excellence, brand trust, customer satisfaction and customer loyalty

Pendahuluan

Loyalitas belakangan ini menjadi isu sentral bagi dunia bisnis dan dianggap sebagai aset yang paling berharga bagi sebuah perusahaan, karena dapat mempengaruhi eksistensi perusahaan dimasa yang akan datang, membuat pelanggan melakukan pembelian secara berulang, membeli dalam jumlah lebih banyak serta merekomendasikan kepada orang lain untuk membeli, sehingga akhirnya membuat return perusahaan dapat dipertahankan atau bahkan dapat meningkat (Yazid, 2006).

Faktor-faktor yang mempengaruhi terbentuknya/terciptanya loyalitas merek antara lain Perceived product superiority (penerimaan keunggulan produk), fortitude (keyakinan yang dimiliki oleh seseorang terhadap merek tersebut), Bonding with the product or company (Keterikatan dengan produk atau perusahaan) dan Customer satisfaction yaitu kepuasan yang diperoleh pelanggan (Schiffman dan Kanuk, 2004).

Mengingat Indonesia sebagai negara agraris sehingga kebutuhan akan pupuk urea di Indonesia cukup besar, disamping pupuk urea bersubsidi untuk kebutuhan sektor pertanian, peluang untuk pupuk urea nonsubsidi juga besar, hal ini didukung oleh sektor perkebunan besar yang banyak terdapat di pulau Sumatera serta kebutuhan urea untuk industri kimia di dalam negeri, oleh karena itu diperlukan respon perusahaan terhadap kebutuhan dan keinginan pelanggan agar tercapai tingkat kepuasan pelanggan dan kerekatan pelanggan (loyalitas pelanggan). Perusahaan yang tidak tanggap menanggapi kebutuhan dan keinginan pelanggan, berarti memberi kesempatan kepada pelanggan untuk mencari dan menemukan, bahkan berpeluang untuk pindah ke produsen atau produk sejenis lainnya yang dapat membuat mereka puas, akibatnya perusahaan akan kehilangan pelanggan dan pesaing akan mendapatkan pelanggan baru. Dengan demikian, manajemen perusahaan dituntut untuk lebih cermat dalam menentukan strategi bersaing, agar dapat memenangkan persaingan yang dihadapi (Rizal, 2007).

PT Pupuk Iskandar Muda juga berkewajiban menyalurkan sejumlah kuota pupuk urea subsidi sesuai rayon yang telah ditetapkan pemerintah dan PT Pupuk Indonesia yaitu Wilayah Pemasaran Sumatera Utara, Kepulauan Riau, Sumatera Barat, Jambi dan Aceh termasuk Aceh Utara di dalamnya. Secara administrasi Kabupaten Aceh Utara meliputi 27 kecamatan dan 852 gampong dengan dengan luas wilayah keseluruhan $\pm 3.296,86 \mathrm{~km}^{2}$, Adapun kebutuhan pupuk urea di Kabupaten Aceh Utara adalah untuk menunjang kegiatan pertanian pada lahan produktif seluas $238.288 \mathrm{Ha}$ atau $72,30 \%$ dari Luas Wilayah Aceh Utara.

PT Pupuk Iskandar Muda menyalurkan sejumlah kuota pupuk urea subsidi untuk Petani di Kabupaten Aceh Utara sesuai RDKK tahun 2018 adalah sebesar 9.953 Ton dan pada tahun 2019 oleh Pemerintah menurunkan lagi hingga menjadi sebesar 7.000 Ton, sedangkan kebutuhannya mencapai 21.944 Ton sehingga mengakibatkan kelangkaan pupuk urea subsidi di kawasan Aceh Utara terutama pada saat musim tanam padi atau musim turun sawah tiba. Hal tersebut akan berdampak lebih fatal pada kecamatan tertentu yang mana terdapat area persawahan yang dapat ditanami dua kali dalam setahun. 
Guna mengantisipasi kelangkaan pupuk untuk kebutuhan petani dan mendukung wacana program pemerintah "Kartu Tani” dalam hal membentuk kesiapan petani terhadap pengalihan subsidi pupuk melalui produsen menjadi subsidi langsung ke petani, PT Pupuk Indonesia selaku perseroan juga telah menugaskan kepada para produsen pupuk termasuk PT Pupuk Iskandar Muda untuk mewajibkan distributornya agar selalu menyiapkan stok pupuk non subsidi di setiap kios pupuk (retail). Untuk menghadapi tantangan tersebut, PT Pupuk Iskandar Muda melakukan berbagai macam langkah startegis dalam memasarkan produk retail salah satunya yaitu dengan menambahkan jumlah tenaga sales baik Sales Representative (SR) maupun Assistant Sales Representatve (ASR) yang disebar ke beberapa kabupaten/kota di wilayah pemasaran PT Pupuk Iskandar Muda.

Berkaitan dengan strategi pemasaran pupuk non subsidi di Kabupaten Aceh Utara yang lebih berorientasi pada upaya untuk mengarahkan para konsumen maupun calon konsumen (konsumen potensial) untuk lebih setia pada produk yang diberikan serta akibat adanya pupuk lain seperti urea, ZA dan pupuk majemuk NPK dari produsen pesaing, maka perlu dilakukan kajian mendalam tentang respon pelanggan pupuk retail yaitu petani yang membeli pupuk urea nonsubsidi produksi PT Pupuk Iskandar Muda pada kios-kios pupuk di Kabupaten Aceh Utara, terutama lebih difokuskan kepada penerimaan keunggulan produk dan keyakinan/kepercayaan pada merek. Disamping itu, loyalitas pelanggan melalui kepuasan pelanggan dalam menggunakan pupuk merek tertentu perlu juga dikaji untuk melahirkan rekomendasi bagi pihak yang berkepentingan.

Berdasarkan data hasil penjualan pupuk urea nonsubsidi PT Pupuk Iskandar Muda yang dipasarkan secara retail pada tahun 2017 dan 2018 terlihat bahwa jumlah pembelian per-bulan oleh pelanggan retail sangat fluktuatif sehingga sebuah fenomena yang menarik untuk dilakukan penelitian lebih lanjut terhadap faktor-faktor yang mempengaruhi jumlah pembelian pupuk urea nonsubsidi PT Pupuk Iskandar Muda oleh pelanggan retail yang disebabkan pengaruh loyalitasnya, sehingga penulis menarik untuk melakukan penelitian dengan mengambil judul "Analisis Faktor-Faktor Yang Mempengaruhi Loyalitas Pelanggan Retail Pupuk Urea Nonsubsidi PT Pupuk Iskandar Muda di Kabupaten Aceh Utara”.

Perumusan Masalah Penelitian

Berdasarkan latar belakang masalah di atas disusunlah beberapa rumusan masalah penelitian, yaitu sebagai berikut:

1. Bagaimanakah pengaruh penerimaan keunggulan produk terhadap kepuasan pelanggan?

2. Bagaimanakah pengaruh kepercayaan pada merek terhadap kepuasan pelanggan?

3. Bagaimanakah pengaruh penerimaan keunggulan produk terhadap loyalitas pelanggan?

4. Bagaimanakah pengaruh kepercayaan pada merek terhadap loyalitas pelanggan?

5. Bagaimana pengaruh kepuasan pelanggan terhadap loyalitas pelanggan?

6. Apakah kepuasan pelanggan memediasi penerimaan keunggulan produk terhadap loyalitas pelanggan?

7. Apakah kepuasan pelanggan memediasi kepercayaan pada merek terhadap loyalitas pelanggan?

Tujuan Penelitian

Setiap penelitian tentunya memiliki tujuan yang ingin dihasilkan oleh peneliti, adapun tujuan penelitian ini adalah sebagai berikut:

1. Untuk mengetahui dan menganalisis pengaruh penerimaan keunggulan produk terhadap kepuasan pelanggan.

2. Untuk mengetahui dan menganalisis pengaruh kepercayaan pada merek terhadap kepuasan pelanggan.

3. Untuk mengetahui dan menganalisis pengaruh penerimaan keunggulan produk terhadap loyalitas pelanggan

4. Untuk mengetahui dan menganalisis pengaruh kepercayaan pada merek terhadap loyalitas pelanggan.

5. Untuk mengetahui dan menganalisis pengaruh kepuasan pelanggan terhadap loyalitas pelanggan.

6. Untuk mengetahui dan menganalisis apakah kepuasan pelanggan memediasi penerimaan keunggulan produk terhadap loyalitas pelanggan.

Kajian Pustaka

Loyalitas Pelanggan

Loyalitas pelanggan merupakan dorongan perilaku untuk melakukan pembelian secara berulang-ulang dan untuk membangun kesetiaan pelanggan terhadap suatu produk atau jasa yang dihasilkan oleh badan usaha tersebut membutuhkan waktu yang lama melalui suatu proses pembelian yang berulang-ulang (Olson, 1993).

Indikator dari loyalitas pelanggan menurut Kotler \& Keller (2006) ada 4, yaitu:

1. Repeat purchase (pembelian berulang);

2. Retention (ketahanan terhadap pengaruh yang negatif);

3. Setia menggunakan produk

4. Referalls (mereferensikan kepada orang lain)

Kepuasan Pelanggan

Hawkins dan Lonney dikutip dalam Tjiptono (2004:101) indikator pembentuk kepuasan terdiri dari:

1. Kesesuaian harapan

2. Minat pembelian ulang

3. Kesediaan merekomendasikan 


\section{Kemudahan mendapatkan}

Berdasarkan penjelasan diatas, dapat disimpulkan bahwa indikator-indikator yang membentuk kepuasan pelanggan adalah kualitas produk sesuai harapan, minat membeli ulang karena kualitas pelayanan yang baik dan bersedia merekomendasikan serta mudah mendapatkannya

Kepercayaan Merek

Kepercayaan merek adalah persepsi akan kehandalan dari sudut pandang konsumen didasarkan pada pengalaman, atau lebih pada urutan-urutan transaksi atau interaksi yang dicirikan oleh terpenuhinya harapan akan kinerja produk dan kepuasan (Ferinnadewi, 2008).

Menurut Delgado dan Walzuch dalam Ferrinadewi (2008), komponen kepercayaan merek bersandar pada penilaian konsumen yang subyektif atau didasarkan pada beberapa persepsi, yaitu:

a) Persepsi konsumen terhadap manfaat yang dapat diberikan produk / merek sehingga yakin dalam menggunakannya.

b) Persepsi konsumen akan reputasi merek, persepsi konsumen akan kesamaan kepentingan dirinya dengan penjual, dan persepsi mereka pada sejauh mana konsumen dapat mengendalikan penjual dan persepsi.

Berdasarkan penjelasan diatas, dapat disimpulkan bahwa indikator-indikator yang membentuk kepercayaan terhadap merek adalah :

1. Keyakinan terhadap produk

2. Nilai Manfaat produk

3. Reputasi merek

4. Kesamaan kepentingan sehingga setia menggunakan produk.

5. Pengendalian (kualitas) produk

Keunggulan Produk

Menurut Henard dan Szimanski (2001) dalam Saifuddin (2012), keunggulan produk adalah superioritas dan atau pembedaan yang lebih tinggi dibandingkan dengan tawaran competitor. Unsur-unsur keunggulan produk, misalnya keunikan, nilai dan keuntungan yang ditawarkan perusahaan harus dilihat dari perspektif pelanggan, yang didasarkan pada pemahaman atas kebutuhan dan keinginan pelanggan, juga dari faktor subjektif mereka (suka dan tidak suka).

Posisi keunggulan produk dipandang dari sisi fungsional maupun dari sisi harga dalam usahanya untuk pemenuhan harapan pelanggan tersebut didukung oleh atribut-atribut fisik yang melekat pada produk tersebut. Jika didasarkan pada Song dan Parry (1997) maka atribut yang mendukung keunggulan produk adalah diferensiasi produk yang komponen-komponennya antara lain adalah produk tersebut harus lebih inovatif dibandingkan dengan produk yang sudah ada, produk tersebut harus dan dapat menjembatani keinginan dari konsumen dengan baik, dalam hal ini diterjemahkan sebagai fungsi daripada produk tersebut.

Berdasarkan penjelasan di atas, dapat disimpulkan bahwa indikator-indikator yang membentuk penerimaan keunggulan produk adalah:

1. Nilai Manfaat

2. Kualitas produk

3. Inovasi pada produk

4. Kemudahan proses mendapatkannya

5. Mereduksi biaya mendapatkannya (mudah dijangkau)

Kerangka Konseptual

Menurut Olson (dalam Saifuddin 2012), Loyalitas pelanggan merupakan dorongan perilaku untuk melakukan pembelian secara berulang-ulang dan untuk membangun kesetiaan pelanggan terhadap suatu produk atau jasa. Menurut Rangkuti (2006) kepuasan pelanggan didefinisikan sebagai respon konsumen terhadap ketidaksesuaian antara tingkat kepentingan sebelumnya dan kinerja aktual yang dirasakannya setelah pemakaian. Menurut Henard dan Szimanski (dalam Saifuddin 2012), keunggulan kompetitif produk adalah superioritas dan atau pembedaan yang lebih tinggi dibandingkan dengan tawaran competitor. Menurut menurut Delgado (dalam Ferrinnadewi, 2008), kepercayaan merek adalah kemampuan merek untuk dipercaya (brand reliability), yang bersumber pada keyakinan konsumen bahwa produk tersebut mampu memenuhi nilai yang dijanjikan dan intensi baik merek (brand intention) yang didasarkan pada keyakinan konsumen bahwa merek tersebut mampu mengutamakan kepentingan konsumen.

Berdasarkan pada uraian teori yang telah dikemukakan serta permasalahan yang ada, maka perlu dibuat sebuah kerangka konseptual penelitian. Tujuannya adalah, untuk memberikan kemudahan dalam mengkaji kondisi yang diteliti. Berdasarkan pemikiran tersebut, maka dapat digambarkan sebuah kerangka pemikiran penelitian seperti pada Gambar berikut ini :

Gambar Kerangka Konseptual Penelitian 
Hipotesis

Dari kerangka konseptual penelitian, dirumuskanlah hipotesis penelitian sebagai berikut:

H1: $\quad$ Keunggulan Produk berpengaruh positif dan signifikan terhadap kepuasan pelanggan.

H2: $\quad$ Kepercayaan Merek berpengaruh positif dan signifikan terhadap kepuasan pelanggan.

H3: Keunggulan Produk berpengaruh positif dan signifikan terhadap loyalitas pelanggan.

H4: $\quad$ Kepercayaan Merek berpengaruh positif dan signifikan terhadap loyalitas pelanggan.

H5: Kepuasan pelanggan berpengaruh positif dan signifikan terhadap loyalitas pelanggan.

H6: Kepuasan pelanggan memediasi pengaruh keunggulan produk terhadap loyalitas pelanggan.

H7: Kepuasan pelanggan memediasi pengaruh kepercayaan merek terhadap loyalitas pelanggan.

Metode Penelitian

Objek dan Lokasi Penelitian

Penelitian ini dilakukan di wilayah pemasaran PT PIM di Kabupaten Aceh Utara dengan pelanggan retail pupuk urea nonsubsidi PT PIM sebagai objek penelitian. Ruang lingkup penelitian meliputi keunggulan produk, kepercayaan merek, kepuasan pelanggan dan loyalitas pelanggan.

\section{Populasi dan Sampel}

Populasi dalam penelitian ini adalah seluruh petani yang membeli pupuk retail urea nonsubsidi PT Pupuk Iskandar Muda di Kabupaten Aceh Utara. Adapun banyaknya jumlah petani selaku pelanggan retail pupuk urea nonsubsidi PT Pupuk Iskandar Muda di Kabupaten Aceh Utara tidak dapat diketahui secara pasti namun diperkirakan sebagian besar berasal dari petani yang tidak mendapat saluran pupuk subsidi karena di luar lingkup yang ditentukan dalam RDKK (Rencana Definitif Kebutuhan Kelompok) sehingga harus membeli pupuk urea non subsidi.

Berhubungan jumlah populasi tidak diketahui maka teknik penarikan sampel dilakukan dengan non probability sampling dengan teknik purposive sampling. purposive sampling merupakan teknik pengambilan sampel yang dilakukan dengan mengambil sampel dari populasi berdasarkan pada suatu kriteria-kriteria a) petani yang membeli pupuk urea retail non subsidi PT PIM , b) petani yang berdomisili di Kabupaten Aceh Utara, c) petani selaku pelanggan yang membeli pupuk urea retail non subsidi PT PIM secara berulang di Kabupaen Aceh Utara. Kriteria-kriteria yang digunakan dapat berdasarkan pertimbangan (judgment) atau jarak (quota) tertentu (Jogiyanto, 2011:79). Jumlah sampel ditentukan atas dasar jumlah kesediaan populasi yang dikaitkan dengan jumlah indikator atau pertanyaan dalam kuisioner. Jumlah indikator dalam penelitian ini adalah sebanyak 18 indikator. Besaran sampel digunakan berpedoman berdasarkan jumlah data yang akan digunakan dalam model analisis structural equation modeling (SEM), yaitu berkisar antara 100-200 (Ferdinand, 2014).

Berdasarkan pandangan tersebut di atas, maka sampel yang ditetapkan dalam penelitian ini adalah 144 responden dengan pertimbangan bahwa ukuran sampel delapan kali dari jumlah indikator yang ada (8 x $18=144$ responden).

Teknik Pengumpulan Data

Teknik pengumpulan data yang digunakan dalam penelitian ini adalah dengan menyebarkan kuesioner kepada responden penelitian dan pengukurannya dengan menggunakan Skala Likert.

Metode Analisis Data

Metode analisis data yang akan digunakan dalam penelitian ini adalah Structural Equation Modelling (SEM) yang dioperasikan melalui program Analysis of Moment Structure (AMOS) berdasarkan data valid dan realiabel melalui pengujian validitas dan reliabilitas.

Full Model

Gambar Full Model Tesis Setelah Modifikasi

Sumber: Data Kuesioner 2019 Diolah Oleh Peneliti Dengan Program AMOS

Dari gambar di atas dapat disimpulkan bahwa secara umum semua konstruk yang digunakan untuk membentuk model penelitian ini setelah dimodifikasi telah memenuhi kriteria goodness of fit yang telah ditetapkan seperti nilai Chi-Square nilai GFI, RMSEA, TLI, CFI, CMIN/DF dan P-Value, kecuali nilai AGFI yang masih marginal $(0,897<0,90)$, namun sudah bisa ditolerir karena sudah mendekati baik seperti yang terlihat pada table berikut ini.

Tabel Kriteria Goodness Of Fit Full Model SetelahModifikasi 


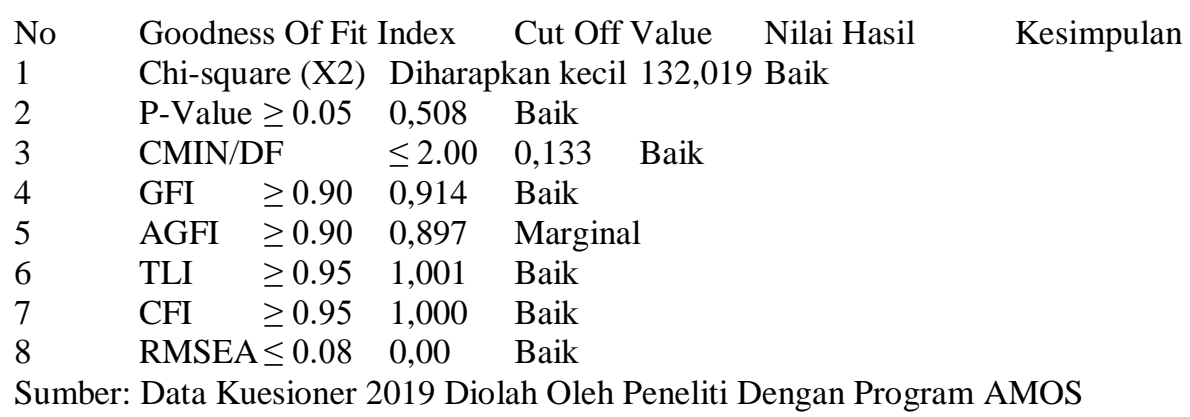

Pengaruh Variabel Eksogen terhadap Variabel Endogen

Untuk melihat seberapa besar pengaruh variabel eksogen terhadap variabel endogen dapat dilihat pada tabel berikut ini.

Tabel Pengaruh Variabel Eksogen Terhadap Variabel Endogen

\begin{tabular}{llllllllll} 
Hubungan Variabel & \multicolumn{1}{l}{ Estimate Std. Est. S.E. C.R. } & P & \multicolumn{1}{l}{ Kesimpulan } & & & \\
Kepuasan Pelanggan & $<---$ & Kepercayaan Merek & 0,670 & 0,606 & 0,204 & 3,288 & 0,001 & Diterima \\
Kepuasan Pelanggan & $<---$ & Keunggulan Produk & 0,114 & 0,111 & 0,185 & 0,616 & 0,538 & Ditolak \\
Loyalitas Pelanggan & $<---$ & Kepuasan Pelanggan & 0,307 & 0,330 & 0,092 & 3,331 & $* * *$ & Diterima \\
Loyalitas Pelanggan & $<---$ & Keunngulan Produk & 0,012 & 0,013 & 0,151 & 0,08 & 0,937 & Ditolak \\
Loyalitas Pelanggan & $<---$ & Kepercayaan Merek & 0,563 & 0,548 & 0,186 & 3,022 & 0,003 & Diterima
\end{tabular}

Sumber: Data Kuesioner 2019 Diolah Oleh Peneliti Dengan Program AMOS

Pengaruh Total, Langsung dan Tidak Langsung

Untuk melihat efek mediasi maka terlebih dahulu akan dilihat seberapa besar pengaruh langsung, pengaruh tidak langsung serta pengaruh total variabel keunggulan produk, kepercayaan merek dan kepuasan pelanggan terhadap loyalitas pelanggan retail pupuk urea non subsidi PT Pupuk Iskandar Muda di Kabupaten Aceh Utara seperti yang ditampilkan dalam tabel berikut ini.

Tabel Pengaruh Total, Langsung dan Tidak Langsung

\begin{tabular}{|c|c|c|c|c|c|c|}
\hline \multirow{2}{*}{$\begin{array}{c}\text { Hubungan Variabel } \\
\text { Pengaruh Tot }\end{array}$} & \multicolumn{3}{|c|}{ Keunggulan Produk } & \multirow[t]{2}{*}{ Kepercayaan Merek } & \multirow[t]{3}{*}{ Kepuasan Pelanggan } & \multirow[t]{2}{*}{ Loyalitas Pelanggan } \\
\hline & & & & & & \\
\hline Kepuasan Pelanggan & 0,111 & 0,606 & - & - & & \\
\hline Loyalitas Pelanggan & 0,050 & 0,747 & 0,330 & - & & \\
\hline \multicolumn{6}{|c|}{ Pengaruh Langsung } & \\
\hline Kepuasan Pelanggan & 0,111 & 0,606 & - & - & & \\
\hline Loyalitas Pelanggan & 0,013 & 0,548 & 0,330 & - & & \\
\hline \multicolumn{5}{|c|}{ Pengaruh Tidak Langsung } & & \\
\hline Kepuasan Pelanggan & - & & - & - & & \\
\hline Loyalitas Pelanggan & 0,037 & 0,199 & - & - & & \\
\hline
\end{tabular}

Uji Mediasi (Intervening)

Baron dan Kenny (1986) menyatakan suatu variabel disebut variabel intervening jika variabel tersebut ikut mempengaruhi hubungan antara variabel independen dan variabel dependen. Salah satu cara yang populer dalam menguji hipotesis mediasi yang dikembangkan adalah uji $\mathrm{Z}$ dari sobel atau yang disebut Zobel Test.

Kepuasan pelanggan memediasi pengaruh keunggulan produk terhadap loyalitas pelanggan Perhitungan nilai signifikansi jalur c' dilakukan dengan menggunakan Kalkulator Sobel Test. Hasil pengujian efek mediasi (intervening) hubungan variabel keunggulan produk dengan variabel loyalitas pelanggan dimediasi oleh variabel kepuasan pelanggan ditampilkan dalam bentuk gambar.

Sumber: Model Mediasi Baron dan Kenny (1986) Dikembangkan Oleh Peneliti 
Dari gambar di atas dapat diidentifikasi bahwa koefisien jalur a, jalur c dan jalur c' tidak memenuhi kriteria yang ditentukan oleh Baron dan Kenny (1986). Dengan demikian dapat disimpulkan bahwa kepuasan pelanggan tidak memediasi (non mediation) hubungan antara keunggulan produk dengan loyalitas pelanggan retail pupuk urea non subsidi di Kabupaten Aceh Utara.

PT Pupuk Iskandar Muda

Kepuasan pelanggan memediasi pengaruh kepercayaan merek terhadap loyalitas pelanggan

Hasil pengujian efek mediasi (intervening) hubungan variable kepercayaan merek dengan variabel loyalitas pelanggan yang dimediasi oleh variabel kepuasan pelanggan dan ditampilkan dalam gambar berikut.

\section{Sumber: Model Mediasi Baron dan Kenny (1986) Dikembangkan Oleh Peneliti}

Dari gambar di atas dapat diidentifikasi bahwa koefisien jalur a, jalur b dan jalur c memenuhi kriteria yang ditentukan oleh Baron dan Kenny (1986). Sedangkan koefisien jalur c' tidak memenuhi persyaratan yang ditentukan oleh Baron dan Kenny (1986). Hal ini berdasarkan ketentuan Baron dan Kenny (1986) bahwa telah terjadi hubungan secara partial mediation. Dengan kata lain kepuasan pelanggan memediasi pengaruh kepercayaan merek terhadap loyalitas pelanggan retail pupuk urea non subsidi PT Pupuk Iskandar Muda di Kabupaten Aceh Utara secara parsial

Pembuktian Hipotesis Penelitian

Untuk mengetahui apakah penelitian ini menerima atau menolak hipotesis yang telah diajukan, maka akan disajikan pembuktian dari hasil pengujian dalam tabel di bawah ini.

Tabel Kesimpulan Hipotesis Penelitian

No Pernyataan Hipotesis Std.Est $\quad$ S.E. $\quad$ C.R. $\quad P \quad$ Kesimpulan

$1 \quad$ Keunggulan produk berpengaruh positif dan signifikan terhadap kepuasan pelanggan retail pupuk urea non subsidi PT Pupuk Iskandar Muda di Kabupaten Aceh Utara. $\quad 0,111 \quad 0,185 \quad 0,616 \quad 0,538 \quad$ Hipotesis Ditolak

2 Kepercayaan Merek berpengaruh positif dan signifikan terhadap kepuasan pelanggan retail pupuk urea non subsidi PT Pupuk Iskandar Muda di Kabupaten Aceh Utara. $\quad \begin{array}{lllll}0,606 & 0,204 & 3,288 & 0,001 & \text { Hipotesis Diterima }\end{array}$

3 Keunggulan Produk berpengaruh positif dan signifikan terhadap loyalitas pelanggan retail pupuk urea non subsidi PT Pupuk Iskandar Muda di Kabupaten Aceh Utara. $\quad \begin{array}{lllll}0,013 & 0,151 & 0,080 & 0,937 & \text { Hipotesis Ditolak }\end{array}$

4 Kepercayaan Merek berpengaruh positif dan signifikan terhadap loyalitas pelanggan retail pupuk urea non subsidi PT Pupuk Iskandar Muda di Kabupaten Aceh Utara. $\quad 0,548 \quad 0,186 \quad 3,022 \quad 0,003 \quad$ Hipotesis Diterima

5 Kepuasan pelanggan berpengaruh positif dan signifikan terhadap loyalitas pelanggan retail pupuk urea non subsidi PT Pupuk Iskandar Muda di Kabupaten Aceh Utara. $\quad 0,330 \quad 0,092 \quad 3,331 \quad * * * \quad$ Hipotesis Diterima

$6 \quad$ Kepuasan pelanggan memediasi pengaruh keunggulan produk terhadap loyalitas pelanggan retail pupuk urea non subsidi $\begin{array}{lllll}\text { PT Pupuk Iskandar Muda di Kabupaten Aceh Utara. } & 0,037 & 0,061 & 0,592 & 0,554\end{array}$ Hipotesis Ditolak

$7 \quad$ Kepuasan pelanggan memediasi pengaruh kepercayaan merek terhadap loyalitas pelanggan retail pupuk urea non subsidi PT Pupuk Iskandar Muda di Kabupaten Aceh Utara. 0,199 $0,087 \quad 2,288 \quad 0,022 \quad$ Hipotesis Diterima

Sumber: Kuesioner 2019 Diolah Dengan Program AMOS dan Sobel Test

Berdasarkan tabel di atas dapat disimpulkan bahwa hipotesis $\mathrm{H} 2, \mathrm{H} 4$ dan $\mathrm{H} 5$ ᄀרdalam penelitian ini diterima dan telah terbukti positif dan signifikan karena nilai Critical Ratio (C.R.) lebih besar dari 2,58 dan nilai probability (P) yang lebih kecil dari nilai signifikansi 0,05. Hipotesis 7 (H7) juga diterima karena berdasarkan hasil perhitungan efek mediasi telah terbukti kepuasan pelanggan memediasi pengaruh kepercayaan merek terhadap loyalitas pelanggan retail pupuk urea non subsidi PT PIM di Kabupaten Aceh Utara secara partial mediation. Sedangkan hipotesis H1 dan H3 ditolak karena terbukti bahwa nilai Critical Ratio (C.R.) H1 dan H3 lebih kecil dari 2,58 dan nilai probability (P) lebih besar dari nilai signifikansi 0,05. Hipotesis 6 (H6?ר) ditolak karena tidak memenuhi kriteria-kriteria uji efek mediasi sebagaimana yang disyaratkan oleh Baron dan Kenny (1986).

Kesimpulan

Berdasarkan tujuan penelitian yang telah dikemukakan pada bagian sebelumnya maka dapat diambil beberapa kesimpulan, yaitu: 1. Kepercayaan merek berpengaruh secara positif dan signifikan terhadap kepuasan pelanggan. Hal ini berarti bahwa semakin tinggi kepercayaan merek yang tumbuh pada pelanggan retail pupuk urea non subsidi PT Pupuk Iskandar Muda di Kabupaten Aceh Utara maka akan semakin meningkatkan pula tingkat kepuasan pelanggan retail pupuk urea non subsidi PT Pupuk Iskandar Muda di Kabupaten Aceh Utara. 
2. Kepercayaan merek mempunyai pengaruh yang positif dan signifikan terhadap loyalitas pelanggan. Hal ini berarti bahwa semakin tinggi kepercayaan merek yang tumbuh pada pelanggan retail pupuk urea non subsidi PT Pupuk Iskandar Muda di Kabupaten Aceh Utara, maka akan semakin meningkatkan pula loyalitas pelanggan retail pupuk urea non subsidi PT Pupuk Iskandar Muda di Kabupaten Aceh Utara.

3. Kepuasan pelanggan berpengaruh secara positif dan signifikan terhadap loyalitas pelanggan. Hal ini berarti bahwa semakin tinggi tingkat kepuasan pelanggan retail pupuk urea non subsidi PT Pupuk Iskandar Muda di Kabupaten Aceh Utara, maka akan semakin meningkatkan loyalitas pelanggan retail pupuk urea non subsidi

PT Pupuk Iskandar Muda di Kabupaten Aceh Utara.

4. Kepuasan pelanggan memediasi pengaruh kepercayaan merek terhadap loyalitas pelanggan retail pupuk urea non subsidi PT Pupuk Iskandar Muda di Kabupaten Aceh Utara secara partial mediation.

Saran

Beberapa saran yang dapat diajukan sebagai masukan kepada Direktur Komersil ataupun General Manager Pemasaran \& Penjualan PT Pupuk Iskandar Muda adalah sebagai berikut:

1. Agar dapat mengupayakan pertumbuhan dan peningkatan kepercayaan terhadap merek PT Pupuk Iskandar Muda terutama pada indikator menumbuhkan keyakinan untuk tidak berpindah kepada merek lain yang mana saat ini telah banyak kompetitor baik dari dari dalam maupun luar negeri (pupuk impor cina) secara gencar memasarkan dan menjalankan persainagan bisnis yang ketat, upaya tersebut dapat dilakukan dengan menciptakan persepsi positif dari konsumen terhadap manfaat yang dapat diberikan produk/merek melalui demonstration plot (Demplot) dengan bekerjasama dengan petani atau masyarakat sehingga akan lebih yakin dalam menggunakan pupuk urea non subsidi PT Pupuk Iskandar Muda.

2. Agar meningkatkan layanan distribusi dan ketersediaan pupuk di kios-kios pupuk serta memberikan informasi melalui promosi yang tidak berlebihan dan tidak sesuai dengan realita yang akan diterima konsumen, untuk mencegah konsumen akan mempunyai pengharapan yang terlalu tinggi, sehingga berakibat ketidakpuasan jika penjual tidak dapat memenuhi informasinya.

3. Mengupayakan peningkatan loyalitas pelanggan dengan memberikan pelayanan lebih kepada pelanggan diataranya dengan memberi perhatian (caring), menumbuhkan kepercayaan (trust), memberi perlindungan (length of patronage), dan menciptakan kepuasan akumulatif (overall satisfaction) meskipun selama ini telah dilakukan melalui program demplot, corporate social responsibility (CSR) dan program lainnya.

\section{Daftar Referensi}

Alpert, Frank H; Kamins, Michael A. (1995). An Empirical Investigationof Consumer Memory Attitude and Perceptions Toward Pioneer and Follower Brands, Journal of Marketing, Vol.59, Iss.4

Cooper. (1994). New product: the factors that drive success, International marketing Review, Vo.11 No.1.

Cooper dan Kleinschimidt. (2000). New product performance: what distinguishes the star products, Australian Journal of Management, Vol.25 No.1.

Ferdinand, Augusty, (2014), Structural Equation Modelling dalam Penelitian Manajemen, FE UNDIP, Semarang.

Ferrinadewi, Erna. (2008). Merek dan Psikologi Konsumen. Yogyakarta: Graha Ilmu

Ghozali, Imam. (2014). Aplikasi Analisis Multivariate dengan Program SPSS, Edisi 3 Semarang : Badan Penerbit Universitas Diponogoro.

(2011). Ekonometrika, Teori, Konsep dan Aplikasi dengan SPSS 17, Semarang : Badan Penerbit Universitas

Diponogoro.

Hair, J. F., Anderson, R. E., Tatham, R. L., \& Black, W. C. (2014). Multivariate Data Analysis. New Jersey: Prentice Hall.

Kotler, Philip. (1990). Dasar Dasar Pemasaran (Wilhelmus W. Bakowatun, alih bahasa), Jilid 1, Edisi Ketiga, Jakarta : Intermedia.

\section{Gramedia.}

(2005). Manajamen Pemasaran (Benyamin Molan, Alih bahasa), Jilid 1 dan 2. Jakarta: PT. Indeks Kelompok

Kotler, P. \& Armstrong, G. (2004). Dasar Dasar Pemasaran ( Sindoro Alexander, alih bahasa), Jilid 2, Edisi IX, Jakarta : PT Indeks.

Kotler, P. \& Keller, K. (2007). Manajemen Pemasaran ( Benyamin Molan, alih bahasa), Jilid 1, Edisi 12, Jakarta : PT Indeks.

Olson, Peter. (1993). Costumer Behavior and Marketing Strategy, Third Edition, Boston : Richard D. Irwan Inc

Rangkuti, Freddy. 2006. Measuring Customer Satisfaction. Jakarta. Gramedia Pustaka Utama

Rizal. (2007). Analisis Faktor-Faktor Yang Mempengaruhi Loyalitas Pelanggan Pupuk PT Petrokimia Gresik di Jawa Timur (Tesis), Surabaya: Universitas Pembangunan Nasional Veteran Jatim.

Saifuddin (2012). Analisis Faktor-Faktor Yang Mempengaruhi Loyalitas Pelanggan Pupuk Urea Nonsubsidi Pada PT Pupuk Iskandar Muda Provinsi Aceh (Tesis), Lhokseumawe : Universitas Malikussaleh.

Schiffman, L.G., \& Leslie, L.Kanuk (2004). Perilaku Konsumen. Edisi Ketujuh, Jakarta : PT Indeks.

Tjiptono, Fandy. (2001). Strategy Pemasaran, Edisi Kedua, Cetakan Pertama, Yogyakarta : Andi offset. 
Www.danielsoper.com, 2013

Yazid, (2006). Faktor-Faktor Yang Mempengaruhi Loyalitas, Jurnal Sinergi, Kajian Bisnis dan Manajemen, Vol. 8, No. 2, ISSN : 1410-9018. 